\title{
DE LA REPRESENTACIÓN MENTAL A LA LECTURA COMPRENSIVA: UN RETO EN ESTUDIANTES DE EGB MEDIA
}

\section{FROM MENTAL REPRESENTATION TO COMPREHENSIVE READING: A STUDENTS' CHALENGE IN MID-LEVEL EDUCATION}

\author{
Carmen Elena Yungán Pinda ${ }^{1}$ \\ Pontificia Universidad Católica Del \\ Ecuador
}

\section{RESUMEN}

Hoy en día, cada proceso educativo es cuestionado desde su eficacia y efectividad en el desarrollo de aprendizajes de los estudiantes. Uno de ellos tiene que ver con la comprensión lectora preocupante en el Ecuador en lo concerniente al bajo índice de motivación

\footnotetext{
1 Unidad Educativa Pelileo (Ambato - Ecuador)
} Pontificia Universidad Católica Del Ecuador carmen.e.yungan.p@pucesa.edu.ec ORCID: https://orcid.org/0000-0001-9897-7271 a la lectura que tienen los estudiantes, por las dificultades que ello conlleva, en la búsqueda de respuestas a esta problemática se hace un recorrido sobre la influencia de la representación mental en la lectura comprensiva, que es la base de todo proceso hasta llegar a la construcción conceptual, que en definitiva es el conocimiento que todo ser humano tiene entorno a algo. El estudio contrasta pensamientos y corrientes de autores que datan sobre la importancia tanto de 
la representación mental desde sus inicios con los hitos del desarrollo y las podas como también de la lectura comprensiva con lo referente a procesos cognitivos. Para dicho recorrido se utiliza el método científico en su fase de análisis y síntesis de la información a través del rastreo de lecturas científicas. Este análisis tiene como eje principal reflexionar sobre la importancia de que el docente comprenda la relación de la representación mental con la comprensión lectora y como ésta influye en el desarrollo del escolar.

PALABRAS CLAVE: Representación mental, procesos cognitivos, lectura comprensiva.

\section{ABSTRACT}

Nowadays, each educational process is questioned from its usefulness and effectiveness in students' learning development, one of them has to do with reading comprehension, that is worrying in Ecuador regarding to reading motivation low rate that students have, due to difficulties that this involves, in answers searching to this problem, a journey is made through mental representation influence in comprehensive reading, since it is the basis of any process until reaching conceptual construction, which in short is the knowledge that every human being has around something. The study contrasts thoughts and authors currents that date from the importance of both mental representation since its development milestone and synaptic pruning as well as comprehensive reading to cognitive processes. For this path, scientific method is used in its analysis phase and information synthesis through scientific readings searching.

This analysis has as main axis to deeply understand by the teacher's point of view the relationship between mental representation and reading comprehension and how it influences scholar development.
KEY WORDS: Mental representation, cognitive processes, comprehensive reading.

\section{INTRODUCCIÓN}

En el ámbito educativo los procesos formativos son altamente cuestionados desde el rol del docente y desde la participación estudiantil. Sin embargo, el desarrollo de procesos cognitivos es un aspecto particular de cada ser humano; su nivel y desarrollo dependen de varios factores como el social, económico y el entorno; para ello se deberá considerar como aspecto vinculante del proceso cognitivo a la representación mental.

Y no puede hablarse de representación mental sin entender primero el aspecto cognitivo, donde etimológicamente "el vocablo cognición se deriva del Latín cognoscere, que se traduce como conocer, y de allí deriva conocimiento. En la actualidad el empleo del término cognición puede tomarse como sinónimo de procesos mentales o también de actividad mental" (Cosacov, 2014, p.3).

Hablar del término cognición cuando se describe la representación mental, es hablar de procesos de aprendizajes y como el tema es muy amplio, se toma como primera referencia: los Hitos del desarrollo de las funciones motoras y visuales las cuáles se presentan desde el nacimiento hasta los 5 años; los hitos del desarrollo del lenguaje y las funciones sociales, que se desarrollan desde el nacimiento hasta los 12 años que es la edad adulta (Guiu Antem \& Leví Orta, 2017, p.6). Por esta razón se debe fomentar la investigación en el aspecto cognitivo, que empieza en la infancia, el cual permite al niño desarrollar un número de capacidades y habilidades; responsable directo en la adquisición y consolidación del conocimiento (Campos, 2018).

Como segunda referencia se contempla las Podas, proceso natural de eliminación neuronal; que tienen que surgir en el momento indicado, para que se elimine lo que no se utiliza y tener 
más espacio para las conexiones, que utilizamos frecuentemente en procesos importantes en el desarrollo del aprendizaje, la cual se desarrolla desde la segunda ola de proliferación y la poda tiene lugar en la infancia o niñez que va desde los 3 años hasta los 9 años, seguido de más y más podas, durante las siguientes etapas como son: la adolescencia que va desde los 10 hasta los 20 años y por último en la edad del adulto joven entre 20 a 30 años período donde es afecta algunas de nuestras facultades mentales más elevadas. El fruto de dichas podas son las huellas dejadas por el aprendizaje y la memorización, claves para el éxito de los niños a largo plazo, en la escuela y en su vida futura, según la Organización para la Cooperación y el Desarrollo Económicos (OCDE, 2007, p.69).

Según Riviére (1987) citado por (Otero, 2016, p. 3), desde el punto de vista de la Psicología Cognitiva existen diferentes terminologías cuando se refiere a representación mental, como: operaciones y estructuras de las que nos hablan los miembros de la Escuela de Ginebra, representaciones proposicionales de Physylyn, imágenes mentales de Kosslyn o Schepard, esquemas de Rumelhart, scripts de Chunk y Abelson, sistemas de producción de Anderson, modelos mentales de Johnson-Laird, representaciones de nivel implícito y explícito de Karmiloff-Smith, representaciones icónicas y simbólicas de Bruner, subsumidores de Ausubel y signos e instrumentos de Vigotsky.

La representación mental definida desde diferentes perspectivas teóricas, es la forma de representar cognitivamente algo real en ausencia de un objeto, el cómo construir una Representación Mental diferente sobre un mismo objeto, para darle sentido al entorno que nos rodea, a través de experiencias directas.

Después de evidenciar el proceso cognitivo en donde se vincula la representación mental, se tiene que abordar como siguiente punto la comprensión lectora como tal, y cómo se concibe actualmente, según (Anderson y Pearson, 1984) citado por (López, 2009, p. 2) es un proceso a través del cual el lector elabora un significado en su interacción con el texto; plantea que el resultado de las experiencias, cuando se realiza la lectura de un texto y se decodifica las ideas principales, ideas secundarias, palabras, párrafos, se llama comprensión lectora. Información que queda almacenada en la memoria y se la relaciona posteriormente con la información más antigua, por lo que es necesario recalcar que el lector obtendrá de la lectura solo lo más relevante, para construir e interpretar el texto cuando lo lea, en donde relacione el significado de la información antigua con la nueva.

Esta investigación busca una revisión bibliográfica desde varias perspectivas y desde diferentes corrientes, para lograr describir la influencia de la representación mental en la lectura comprensiva, la cual es necesaria e ineludible para acceder al conocimiento dentro del campo educativo, como también de la vida cotidiana de los estudiantes en escolaridad.

\section{DESARROLLO}

Los aportes sobre Representación mental son extensos, sin embargo se resaltará lo más relevante, para que pueda ser comprendido a nivel educativo y de igual manera, se abordará como aspecto vinculante, el proceso cognitivo.

Con el propósito de argumentar la Representación Mental, hoy en día se puede contar con conceptos epistemológicos, como (Piaget \& Inhelder, 1997) precursores de la corriente constructivista, Kintsch (1998) con su modelo de construcción-integración, Ausubel citado por (Otero, 2016) y Bruner, 2010, todos ellos contribuyen con aportes relevantes sobre representaciones mentales. 
Según (Piaget \& Inhelder, 1997) las representaciones mentales llamadas semióticas o simbólicas, son el segundo período de los Estadios del Desarrollo Intelectual, denominado Preoperacional, donde el aprendizaje es significativo, con lo cual es necesario que el niño desarrolle completamente la inteligencia representacional; que no solo se limite a imaginar, sino que también, desarrolle el lenguaje $\mathrm{y}$, de esta manera, pueda construir un discurso lógico a partir de preposiciones verbales, independientes de su conocimiento sobre los objetos (pp. 59-61).

A continuación tenemos a Kintsch citado por (Neyra, 2009, p. 3-9) con el modelo de construcción-integración el cuál manifiesta tener tres niveles de esquemas o representación mental; una a partir de procesamiento de textos denominado código de superficie, la otra a través de la síntesis de las oraciones utilizadas en el texto denominado texto-base y por último el modelo de situación para diagnosticar como se genera la comprensión o interpretación de lo que leemos, donde se infiere que información es relevante o esencial y que información debe ser descartada.

En lo que respecta al autor Ausubel citado por (Otero, 2016, p.2) la representación mental es toda posición teórica que establece que no conocemos el mundo directamente sino que lo representamos por medio de símbolos, esquemas, operaciones, modelos mentales, imágenes, proposiciones, conceptos. Es decir que la conducta está regulada y regida por ellas y no por el ambiente externo.

Para (Bruner, 2010, p.3-4) la Representación Mental es un conjunto de reglas mediante las cuales se puede conservar aquello experimentado en diferentes acontecimientos. Representar es guardar en la memoria aspectos de la experiencia, utilizando para ello algún código regido por reglas, donde propone la existencia de tres sistemas básicos de representación presentes en la cognición humana: 1. La representación metafórica, o de esquemas motores; 2. La representación icónica, mediante imágenes de objetos o eventos, y 3 . La representación simbólica, usando sistemas formales como el lenguaje.

El estudiante elabora representaciones mentales como proposiciones, imágenes mentales, modelos mentales, forma conceptos esenciales a través de oraciones redactadas, referentes al concepto señalado, según Matute, Iglesias, Gutiérrez, Capote, Rojas y Durán (2013).

Para un mejor discernimiento de Comprensión Lectora, se aborda como punto referencial al lenguaje, el cual está vinculado a la lectura.

La mente, el cerebro y la educación aborda muchas facetas de los inmensos desafíos para la educación relacionados con el desarrollo del cerebro, la plasticidad neuronal, la psicología del desarrollo, el aprendizaje del lenguaje y la lectura, de los cuáles para nuestro estudio abordaremos lo concerniente al aprendizaje del lenguaje y al aprendizaje de la lectura (Battro, Fischer, \& Léna, 2016, p. 18).

El lenguaje es una de las principales funciones cognitivas de los seres humanos, para comunicarse entre sí y de donde se desprende el desarrollo de otras capacidades; además hay que mencionar las bases neuroanatómicas del lenguaje, las cuáles son muy complejas, porque están situadas en el cerebro del hemisferio izquierdo denominado dominante; localizado en el Sistema Nervioso Central (Guiu Antem \& Leví Orta, 2017).

Con referencia al mismo tema el autor (Flavell, 2019 , p. 108) manifiesta que los cambios evolutivos como lo cita Piaget al realizar la descripción del desarrollo cognitivo se producen en la segunda infancia, en la tercera infancia se producen los cambios en el conocimiento social, percepción, memoria y lenguaje. Las 
competencias cognitivas y los cambios más realistas suceden en el primer año (inteligencia sensoriomotora), a los 3 años (preoperacional), a los diez años (operacional concreta), en el adolescente a los quince años (Operacional formal).

Esta serie de procesos cognitivos complejos de transformación de la información de códigos se los puede observar en los niños al cumplir aproximadamente dos años, el número de sinapsis (conexiones) alcanza los niveles del adulto, y después aumenta rápidamente entre los cuatro y los diez años, y supera con creces el nivel de los adultos. Durante este periodo de crecimiento de las sinapsis (conexiones), se produce un proceso concurrente de poda al morir las conexiones que no se utilizan. Este proceso puede ayudar a explicar las bases neurológicas de los periodos sensibles o críticos del desarrollo. El orden de aparición de los hitos del desarrollo, incluyendo el habla, es regular en la especie: no depende ni de la cultura ni del idioma que se esté aprendiendo (Berko y Bernstein, 2010, pag. 17-18).

El proceso cognitivo de la comprensión lectora, se inicia con el análisis del lenguaje en sí y su desmembramiento en cuatro "meta-habilidades" que son: La comprensión oral, la producción oral que son componentes esenciales en el procesamiento del lenguaje, habilidades que incluye la memorización a corto plazo, discriminación de sonidos, distinción de palabras e identificación de categorías gramaticales; la lectura y la escritura, de acuerdo a la transmisión o recepción y los medios de comunicación (OCDE, 2007, p. 48).

A continuación un análisis del lenguaje a lo largo de la historia; puesto que la humanidad ha utilizado algún tipo de lengua para comunicarse y facilitar de esta manera la comprensión entre los seres humanos; pero dicho proceso llevó varios miles de años. La evolución del Lenguaje analizado por Wolf, descubre que es un notable hecho cognitivo logrado por las primeras escrituras, como los sistemas cuneiforme y jeroglífico, ya que cuando se concibió el alfabeto, se comenzó con los sonidos vocales, como en el lenguaje ugarítico; para que los griegos, añadan luego, las consonantes para poder describir los fonemas de su idioma. Es decir que leer en los tiempos antiguos no era tan fácil, porque las palabras no estaban separadas por espacios o por puntos (Battro, Fischer, \& Léna, 2016, p. 45).

Ahora bien la proeza cognitiva, implicada al momento de leer, el cual se inventó aproximadamente hace cinco mil cuatrocientos años, tiene que ver con los principios de la lectura que son una mezcla de variables, una combinación de elementos de sonidos que van desde palabras enteras hasta sílabas, rimas o fonemas. La velocidad con la que el cerebro puede aprender los sistemas de lectura, parece haber provocado en el curso de los siglos, la selección de un pequeño grupo de formas de letras que son usadas en nuestro sistema visual para codificar, el leer es considerablemente complejo por la fonología, la semántica y la gramática. Complejo porque el niño debe aprender las reglas de la correspondencia grafema-fonema; leer es un ejemplo de esta capacidad humana de reacomodación mental, y cuanto más se conoce acerca del proceso de lectura del cerebro, mejor los educadores y los estudiantes, pueden tratar las dificultades de la lectura (Battro et al., 2016, pag. 329-335).

El interés por la comprensión lectora no es nuevo, puesto que los educadores año tras año, han buscado la fórmula mágica para que el estudiante o cualquier persona que lea, pueda extraer el mismo significado al leer un texto, que obviamente puede variar en su forma, más no en su contenido. Por ello se debe aclarar que la comprensión lectora no se desarrolla sin la presencia de representación mental, proceso necesario para que el escolar al momento de leer interprete y entienda de forma global el 
texto; cuando un niño comprende y lo representa mentalmente quiere decir que aprendió y decodificó la información, de esta manera el conocimiento se traslada a la memoria a largo plazo el cual para interpretar textos con contenidos más abstractos.

Lo más importante con este análisis es lograr que el estudiante represente mentalmente lo leído, lo que da paso automáticamente a la transición lectora. Proceso necesario para lograr un efecto positivo, como el de eliminar el efecto negativo en el aspecto académico de los estudiantes en la etapa de escolar. Cuando se habla de lo positivo para el estudiante, son las estrategias y metodologías de enseñanza por parte de los docentes con lo concerniente a la lectura, que dará como resultado mejores notas en el resto de áreas académicas. En el aspecto negativo, el escolar que no tiene éxito en el estudio, es por la ausencia de comprensión lectora, puesto que todo lo que se le envía a estudiar al alumno, tiene que ser leído y al no comprenderlo dará como resultado un desinterés en el estudio así como también la deserción escolar.

Es imprescindible que el docente comprenda la influencia de la representación mental en el proceso de lectura comprensiva, para mejorar el proceso de enseñanza - aprendizaje, este último término, desde una perspectiva psicológica puede ser definido como un cambio en la eficiencia o el uso de los procesos cognitivos básicos, conscientes e inconscientes, que promueven una resolución de problemas y un desempeño más eficaz en las tareas de la vida cotidiana (OCDE, 2007, pág. 336).

\section{CONCLUSIONES}

Por todo lo expuesto se concluye que para que exista una representación mental, una simbología, en la memoria a corto plazo y luego sea transferida dicha información a la memoria a largo plazo, se debe dominar el aspecto cognitivo seguido del proceso de escritura y lectura del escolar; que no difiera en sí, del contenido de la información que se le envía a estudiar o a leer al estudiante, lograr de esta manera el dominio de la comprensión lectora.

En síntesis es importante desarrollar primero la representación mental en su debido momento para que exista la comprensión lectora, proceso básico para desarrollar las habilidades de interpretar, decodificar una lectura y no realizarlo mecánicamente, reflexionar lo que realmente ha aprendido de la lectura y vincularlo o relacionarlo a los conocimientos previamente adquiridos como prerrequisito para alcanzar el aprendizaje significativo en los niños.

Debido a la complejidad del proceso cognitivo, la representación mental que no se desarrolla en su debido periodo, dará como resultado dificultades para adquirir los conocimientos necesarios para la etapa escolar; este proceso es necesario para que los aprendizajes significativos sean de calidad, ya que, al no desarrollarlo, el escolar tendrá contratiempos al leer, escribir y por ello, no desarrollará la comprensión lectora; esencial en toda la vida estudiantil.

La información del aspecto cognitivo es relevante para la comunidad educativa, y así se comprenderá la vinculación de la representación mental con la comprensión lectora, que facilita al profesorado con conocimientos referentes a las funciones del cerebro, y en su labor promueva en el estudiante, la disposición por aprender, mediante la comprensión lectora, factor básico en el proceso de enseñanza-aprendizaje.

De igual manera hoy en día se necesita escolares, que utilicen sus habilidades de diferenciación en una lectura, como también de un análisis crítico; estudiantes que sean capaces de decodificar un mensaje o información, saber resumir una lectura, explicar en sus propias palabras, parafrasear párrafos, que dominen el significado de las palabras, para que su comprensión sea de manera automática, fluida y permanente, base 
en la construcción conceptual derivada de la adecuada estructuración de Representaciones Mentales.

\section{REFERENCIAS BIBLIOGRÁFICAS}

> Battro, A. M., Fischer, K. W., \& Léna, P. J. (2016). El cerebro educado: Ensayos sobre la neuroeducación. Recuperado de http://ebookcentral.proquest.com/lib/ pucesp/detail.action?docID $=4909190$

$>$ Berko, J., \& Bernstein, N. (2010) Desarrollo del lenguaje. Recuperado de http://www.herrerobooks.com/pdf/ ALHA/9788483225196.pdf

> Bruner, J. (2010). Dos teorías cognitivas, dos formas de significar, dos enfoques para la enseñanza de la ciencia. Recuperado de https://www.redalyc.org/ pdf/4975/497552357008.pdf

$>$ Campos, A. (2014). Los aportes de la neurociencia a la atención y educación de la primera infancia. Recuperado de https://www.unicef.org/bolivia/056_ NeurocienciaFINAL_LR.pdf

$>$ Cosacov, E. (2014). Introducción a la psicología (7a. Ed). Recuperado de http://ebookcentral.proquest.com/lib/ pucesp/detail.action?docID $=3221498$

> Flavell, J. H. (2019). El desarrollo cognitivo. Antonio Machado Libros. Recuperado de https://books.google.es/ books?id=lee4DwAAQBAJ

> Guiu Antem, J. M., \& Leví Orta, G. (2017). Bases neurológicas de las enfermedades cognitivas del desarrollo y su tratamiento educativo. Recuperado de http://ebookcentral.proquest.com/lib/ pucesp/detail.action?doclD $=5214566$

$>$ Matute, S., Iglesias, P., Gutiérrez, O., Capote, T., Rojas, J., \& Durán, R.
(2013). Representaciones mentales en el aprendizaje del concepto combustión. 11. Recuperado de https://www.redalyc. org/articulo.oa?id=35630152015

$>$ Neyra, T. T. (2009). Representaciones mentales: Discusión crítica del modelo de situación de Kintsch. 29. Recuperado de https://www.redalyc.org/ pdf/1345/134513178006.pdf

> Otero, M. R. (2016). Psicología cognitiva, representaciones mentales e investigación en enseñanza de las ciencias. Recuperado de https://www. if.ufrgs.br/cref/ojs/index.php/ienci/ article/view/651/442

> Piaget, J., \& Inhelder, B. (2007). Psicología del niño. Ediciones Morata. Recuperado de https://books.google. com.ec/books?id=etPoW_RGDkIC

$>$ OCDE. (2007). La comprensión del cerebro. El nacimiento de una ciencia del aprendizaje. Recuperado de https://read.oecd-ilibrary.org/ education/la-comprension-del-cerebroel-nacimiento-de-una-ciencia-delaprendizaje_9789567947928-es\#page6 